Б. Т. Кононов, Ю. Д. Мусаїрова, О. Є. Куян

Харківський національний університет Повітряних Сил імені Івана Кожедуба, Харків

\title{
ВИКОРИСТАННЯ ЕЛЕКТРОГІДРАВЛІЧНИХ АНАЛОГІЙ ПРИ ДІАГНОСТУВАННІ ТЕХНІЧНОГО СТАНУ БЕНЗИНОВИХ ТА ДИЗЕЛЬНИХ ДВИГУНІВ ВНУТРІШНЬОГО ЗГОРЯННЯ
}

\begin{abstract}
3'ясовується зв'язок між явищами,що відбуваються в гідравлічних та електричних системах шляхом порівняння процесів руху рідини в магістральних нафтопроводах та процесів, що відбуваються в лініях електропередачі 3 розподіленими параметрами. Встановлюються гідравлічні і електричні аналоги, а саме тиск рідини та напруга, витрата рідини та струм, гідравлічне коло представляється у вигляді електричного кола, визначаються поняття гідравлічного активного опору, гідравлічної індуктивності та гідравлічної ємності. Пропонується розглядати гідравлічні системи як динамічні ланки, зміни значень параметрів котрих доцільно застосовувати для оцінювання технічного стану бензинових або дизельних двигунів внутрішнього згоряння, використовуючи при цьому такі фізичні величини, що характеризують роботу систем двигунів, як тиск та витрата рідини, і визначаючи технічний стан цих систем шляхом з'ясування зміни амплітудних, частотних, фазових та часових характеристик динамічних кіл, створених гідравлічними активними опорами, гідравлічними індуктивностями та гідравлічними ємностями.
\end{abstract}

Ключові слов а: двигуни внутрішнього згоряння, електрогідравлічні аналогії, динамічні ланки, гідравлічний активний опір, гідравлічна індуктивність та гідравлічна ємність, технічна діагностика гідравлічних систем.

\section{Вступ}

Постановка проблеми. Дієвим засобом дослідження явищ та процесів, що мають місце в механічних, електричних, гідравлічних та пневматичних системах зразків озброєння та військової техніки є математичне моделювання, яке здійснюється за допомогою систем рівнянь, які отримуються з використанням основних постулатів фізики, механіки та електротехніки і враховують принцип Ж. Д. Аламбера, закони I. Ньютона, Г. Кірхгофа, Дж.К. Максвелла та Г.С. Ома.

Сдність рівнянь, що описують явища, які відбуваються в різних за своєю природою системах, дає підставу стверджувати, що дослідження процесів в механічних, гідравлічних та пневматичних системах може бути замінено дослідженням аналогічних процесів в електричних системах, оскільки моделювання процесів в електричних колах цих систем не приводить до появи суттєвих труднощів, властивих механічним, гідравлічним та пневматичним системам, електричні системи більш компактні, вимірювання параметрів цих систем більш прості, а результати цих вимірювань більш точні, що свідчить на користь використання, так званих, електромеханічних, електрогідравлічних та електропневматичних аналогій, які базуються на систематичному переносі теорії електричних кіл в механіку, гідравліку та пневматику. 3'ясуємо, як можливо використати основні положення електрогідравлічної аналогії для аналізу технічного стану систем змащення, охолодження та паливоподачі бензинових й дизельних двигунів автономних та резервних військових електростанцій й силових установок зразків бронетанкової та автомобільної техніки.

Аналіз останніх досліджень і публікацій. Метод електрогідравлічної аналогії знайшов широке використання при розгляді процесів руху рідини в магістральних нафтопроводах [1-3]. Цей метод використовується при моделюванні режимів роботи відцентрових насосів, гідроприводу та інших елементів, що входять до складу гідравлічних систем [24].

В відомій літературі [4-14] електрогідравлічні аналоги розглядались лише для випадку моделювання в системах 3 розподіленими параметрами. Зрозуміло, що електрогідравлічні аналогії можуть використовуватися для гідравлічних систем, в яких параметри елементів цих систем можуть розглядатися в якості зосереджених параметрів.

Мета статті - обгрунтування можливості використання електрогідравлічних аналогій при оцінюванні технічного стану систем дизельних та бензинових двигунів.

\section{Виклад основного матеріалу}

Можливість використання методу електрогідравлічної аналогії підтверджується прикладом порівняння системи рівнянь для потоку рідини в нафтопроводі [2] 3 системою рівнянь, що описує взаємозалежність електричних параметрів в лінії з розподіленими параметрами [15]. Так, диференціальні рівняння в часткових похідних для потоку рідини в нафтопроводі мають ттакий вигляд

$$
\begin{aligned}
& -\frac{\partial P}{\partial x}=\frac{2 a}{S} Q+\frac{\rho_{0}}{S} \frac{\partial Q}{\partial t} ; \\
& -\frac{\partial Q}{\partial x}=\frac{S}{\rho_{0} C^{2}} \frac{\partial P}{\partial t},
\end{aligned}
$$

де $P$ - тиск рідини; $Q$ - витрата рідини; $S$ - площа поперечного перерізу нафтопроводу; $\rho_{0}$ - щільність рідини; $C$ - швидкість звуку в рідині; $a$ - коефіцієнт в'язкого тертя, що визначається втратами кінетичної енергії в нафтопроводі; $x$ - відстань від початку нафтопроводу.

Відповідні диференціальні рівняння в часткових похідних для лінії електропередачі з розподіленими параметрами без врахування втрат в ізоляції записуються таким чином: 


$$
\begin{aligned}
& -\frac{\partial U}{\partial x}=R I+L \frac{\partial I}{\partial t} \\
& -\frac{\partial I}{\partial x}=C \frac{\partial U}{\partial t}
\end{aligned}
$$

де $U, I-$ напруга та струм на відстані $x$ від початку лінії; $R, L, C$ - активний опір, індуктивність та ємність, віднесені до одиниці довжини лінії.
Співставлення (1) та (2) дає підставу стверджувати, що диференціальні рівняння для потоку рідини в нафтопроводі та диференціальні рівняння лінії електропередачі з розподіленими параметрами ідентичні.

Фізичні величини, що входять в ці рівняння, подібні та існує аналогія між ними, відомості щодо якої наведені в табл. 1.1.

Таблиия 1 - Електричні та гідравлічні аналоги

\begin{tabular}{|c|c|c|c|c|c|}
\hline Система & \multicolumn{2}{|c|}{ Фізичні величини } & \multicolumn{3}{|c|}{ Параметри елементів } \\
\hline \multirow{2}{*}{ Електрична } & Напруга & Струм & Активний & Електрична & Електрична ємність \\
& $U, \mathrm{~B}$ & $I, \mathrm{~A}$ & опір $R$, Ом & індуктивність $L$, Гн & $C$ \\
\hline \multirow{2}{*}{ Гідравлічна } & Тиск $P$, Па & $\begin{array}{c}\text { Витрата } \\
Q \mathrm{~m}^{3} / \mathrm{c}\end{array}$ & $\begin{array}{c}\text { Гідравлічний опір } \\
R_{2}=\frac{2 a}{S}, \mathrm{c} \cdot \text { Па } / \mathrm{m}^{3}\end{array}$ & $\begin{array}{c}\text { Гідравлічна індуктив- } \\
\text { ність } L_{2}=\frac{\rho_{0}}{S}, \mathrm{c}^{2} \cdot \text { Па } / \mathrm{m}^{3}\end{array}$ & $\begin{array}{c}\text { Гідравлічна ємність } \\
C_{2}\end{array}$ \\
& & & $\frac{S}{\rho_{0} C^{2}}, \mathrm{~m}^{3} / \Pi а$ \\
\hline
\end{tabular}

Розмірності в табл. 1 наведені з урахуванням того, що витрата $Q$ вимірюється в $\mathrm{m}^{3} / \mathrm{c}$, а тиск $P$ вимірюється в Паскалях, де 1 Па $=\kappa \Gamma / \mathrm{M}^{2} \mathrm{c}^{2}$, а між напором $H$ та тиском $P$ існує наступний зв'язок

$$
H=P / \rho g \text {, }
$$

де $g$ - прискорення вільного падіння, м/ $\mathrm{c}^{2} ; \rho-$ щільність рідини, кг/м³.

Таким чином, гідравлічний опір визначається втратами на тертя і обернено пропорційний перерізу гідравлічних ліній, гідравлічна індуктивність обумовлюється інерцією рідини, що переміщується в нафтопроводі, в якій накопичується кінетична енергія, а гідравлічна ємність є елементом, в якому накопичується потенційна енергія і визначається податливістю, обернено пропорційною жорсткості гідравлічної рідини. Зрозуміло, що будь-яку складну гідравлічну систему можливо розглядати як електричну систему, в якій елементи $R_{2}, L_{2}$ та $C_{2}$ з'єднані послідовно або паралельно. Визначаючи вхідний опір кожної ділянки гідравлічної системи, користуючись при цьому методами теорії електричних кіл [15], можливо знайти вхідний опір всієї гідравлічної системи, що включає зосереджені неоднорідності типу фільтрів, зворотних та запобіжних клапанів, місцевих опорів тощо, та, аналізуючи зміни у часі вхідного опору гідравлічної системи, можливо зробити висновок щодо технічного стану цісї системи або стану іï окремих елементів.

Вважаючи, що гідравлічні системи бензинового або дизельного двигуна внутрішнього згоряння, а саме система паливоподачі, система змащення і система охолодження представляються як системи, до складу яких входять такі простіші елементи як активний гідравлічний опір $R_{2}$ з постійною або змінною (що регулюється) площею прохідного перерізу, зосереджена ємність $C_{2}$, величина якої є постійною або змінною та гідравлічна індуктивність, що визначається взаємодією маси $m$ робочої рідини та елементів гідравлічних систем, тобто $L_{2}$, та враховуючи те, що простіші елементи з’єднані паралельно, тобто тиск, що діє на ці елементи однаковий, а насоси в цих системах включені через фільтр, активний опір якого дорівнює $R_{\phi}$, складемо наступне диференціальне рівняння для визначення витрати рідини через паралельно з'єднані $R_{2}, L_{2}$ та $C_{2}$. Користуючись аналогічним співвідношенням для електричних кіл з паралельним з'єднанням $R, L, C$, отримуємо

$$
\frac{1}{R_{2}} P+C_{2} \frac{d P}{d t}+\frac{1}{L_{2}} \int_{0}^{t} P d t=Q .
$$

Після перетворення (4) до стандартного вигляду маємо

$$
C_{2} \frac{d^{2} P}{d t^{2}}+\frac{1}{R_{2}} \frac{d P}{d t}+\frac{1}{L_{2}} P=\frac{d Q}{d t} .
$$

Вводячи позначення оператора диференціювання $S=\frac{d}{d t}$, представимо (5) в вигляді

$$
\left(C_{2} S^{2}+\frac{1}{R_{2}} S+\frac{1}{L_{2}}\right) P=S Q
$$

або отримуємо, що

$$
\begin{gathered}
Q=Y(S) \cdot P, \\
Y(S)=\frac{S^{2} C_{2}+\frac{S}{R_{2}}+\frac{1}{L_{2}}}{S} .
\end{gathered}
$$

Втрати тиску $\Delta P$ на фільтрі дорівнюють

$$
\Delta P=Q \cdot R_{\phi} .
$$

Вважаючи, що тиск перед фільтром дорівнює $P_{1}$, а тиск після фільтру дорівнює $P_{2}$, запишемо

$$
\begin{aligned}
P_{1} & =P_{2}+\Delta P=P_{2}+Q R_{\phi}= \\
& =P_{2}+P_{2} R_{\phi} Y(S)= \\
& =P_{2}\left[1+Y(S) R_{\phi}\right] .
\end{aligned}
$$


Враховуючи (9), отримуємо наступне диференціальне рівняння для визначення закономірності зміни тиску у часі

$$
R_{\phi} C_{2} \frac{d^{2} P_{2}}{d t^{2}}+\frac{R_{\phi}+R_{2}}{R_{2}} \frac{d P_{2}}{d t}+\frac{R_{\phi}}{L_{2}} P_{2}=\frac{d P_{1}}{d t} .
$$

Вільні складові рішення (10) знаходять, зазвичай, з виразу

$$
P_{2}(t)=A_{1} e^{S_{1} t}+A_{2} e^{S_{2} t}
$$

де $A_{1}$ та $A_{2}$ - постійні коефіцієнти, які знаходять 3 початкових умов та законів комутації, відповідно до яких витрата через такий елемент гідравлічної системи як гідравлічна індуктивність миттєво не змінюється, а тиск на такому елементі гідравлічної системи як гідравлічна ємність в початковий момент часу перехідного процесу лишається незмінним; $S_{1}$ та $S_{2}$ - корені характеристичного рівняння

$$
R_{\phi} C_{2} S^{2}+\frac{R_{\phi}+R_{2}}{R_{2}} S+\frac{R_{\phi}}{L_{2}}=0 .
$$

Значення $S_{1}$ та $S_{2}$ знаходяться таким чином:

$$
S_{1,2}=-\delta \pm \sqrt{\delta^{2}-\omega_{0}^{2}}
$$

$$
\text { де } \begin{aligned}
\delta & =\frac{R_{\phi}+R_{2}}{R_{\phi} C_{2} R_{2}}-\text { ступінь затухання; } \\
\omega_{0} & =\sqrt{\frac{1}{C_{2} L_{2}}}-\text { частота коливань. }
\end{aligned}
$$

Зміна в процесі експлуатації двигуна внутрішнього згоряння значень $R_{\phi}, R_{2}, L_{2}$ та $C_{2}$ приводить до зміни характеру перехідного процесу в системі паливоподачі, змащення або охолодження, що може бути використано для оцінювання технічного стану цих систем. Спроба використовувати в якості показника діагностування тиск в гідравлічних системах [16] не дозволяє отримати необхідну точність оцінювання технічного стану цих систем й в деяких обставинах ця оцінка може бути неоднозначною, оскільки на результати оцінювання впливають нестаціонарні режими руху рідини, при яких значення гідравлічних опорів як окремих елементів системи так і всієї системи можуть змінюватися в широкому діапазоні. Удосконалення цього способу оцінювання технічного стану двигуна внутрішнього згоряння, запропонованого в [17], відповідно до якого в якості діагностичного показника слід використовувати відносні зміни тиску рідини в гідравлічних системах та порівнювати ці зміни із граничними значеннями, лише частково усуває неоднозначність результатів оцінювання технічного стану. Справа, в цьому випадку, полягає в тому, що в нестаціонарних режимах роботи гідравлічних систем дуже складно 3'ясувати дійсні причини зміни тиску. В [18] запропоновано, проводячи аналіз стану гідравлічної системи $з$ позицій електрогідравлічної аналогії, використовувати в якості діагностичного показника власну частоту коливань в гідравлічній системі під час перехідного процесу, який викликаний наперед заданими збуреннями. При цьому в [18] доведено, що по мірі зносу деталей двигуна внутрішнього згоряння відбувається зменшення власної частоти коливань тиску, що викликає зростання відносної величини власної частоти коливань тиску $\overline{\omega_{0}}(t)$, яка визначається з виразу

$$
\overline{\omega_{0}}(t)=\frac{\omega_{0}\left(t_{0}\right)-\omega_{0}(t)}{\omega_{0}\left(t_{0}\right)}
$$

де $\omega_{0}\left(t_{0}\right), \omega_{0}(t)$ - власна частота коливань тиску гідравлічної системи, отримана перед початком експлуатації двигуна внутрішнього згоряння та власна частота коливань тиску в довільний, наприклад, момент часу $t$, в який проходить контроль.

Діапазон використання способу оцінювання технічного стану двигуна внутрішнього згоряння, запропонованого в [18], обмежується варіантами гідравлічних систем, у яких гідравлічні параметри $R_{\phi}, R_{2}, L_{2}, C_{2}$ підібрані так, що їх значення обумовлюють коливальний характер перехідного процесу, коли в співвідношенні (13) $\left.\omega_{0}\right\rangle \delta$. У тих випадках, коли значення цих гідравлічних параметрів обумовлюють аперіодичний характер перехідного процесу, тобто тоді, коли $\delta>\omega_{0}$, цей спосіб оцінювання технічного стану двигуна внутрішнього згоряння не може бути використаний.

Разом $з$ тим, метод електрогідравлічних аналогій вказує на дві можливості подолання вказаної обмеженості.

Перша з них, так звана “фазова”, полягає в тому, що в якості діагностичного показника слід використовувати зсув за фазою між пульсаціями тиску рідини на вході та виході фільтра [19]. При використанні фазового методу оцінювання технічного стану двигуна внутрішнього згоряння [20] в контролюємі моменти часу $t_{i}$ та $t_{i+1}$ при заданій частоті пульсацій тиску рідини, наприклад, рівній $\omega(t)=\omega_{0}$, вимірюють кути зсуву за фазою $\phi\left(\omega_{0}, t_{i}\right)$ та $\phi\left(\omega_{0}, t_{i+1}\right)$, визначають різницю між кутами зсуву за фазою пульсацій тиску рідини й обчислюють швидкість зміни різниці фаз відповідно до формули

$$
V=\frac{\phi\left(\omega_{0}, t_{i+1}\right)-\phi\left(\omega_{0}, t_{i}\right)}{t_{i+1}-t_{i}}
$$

та знаходять значення абсолютного відхилення кута зсуву за фазою $\Delta \phi\left(\omega_{0}, t_{i+1}\right)$, яке визначається таким чином:

$$
\Delta \phi\left(\omega_{0}, t_{i+1}\right)=\left|\phi\left(\omega_{0}, t_{i+1}\right)-\phi_{\partial}\right|,
$$

де $\phi_{\partial}$ - допустиме значення кута зсуву за фазою. За цим методом допустимий час роботи гідравлічної системи без проведення іiї обслуговування $T_{\partial}$ визначають з виразу 


$$
T_{\partial}=\frac{\Delta \phi\left(\omega_{0}, t_{i+1}\right)}{V} .
$$

В разі використання іншого ("часового") способу подолання зазначеної обмеженості при $\delta>\omega_{0}$ в варіанті використання способу оцінювання технічного стану двигуна внутрішнього згоряння [18] пропонується в якості показника для оцінювання технічного стану двигуна внутрішнього згоряння обирати тривалість перехідного процесу $\tau$ при зміні тиску в гідравлічній системі, яка в випадку аперіодичного характеру перехідного процесу визначається меншим значенням модуля кореня $S_{1}$ характеристичного рівняння (12), тобто

$$
\tau_{a}=k\left|-\delta+\sqrt{\delta^{2}-\omega_{0}^{2}}\right|,
$$

а в випадку коливального характеру перехідного процесу

$$
\tau_{k}=k \delta,
$$

де $k$ - коефіцієнт, який, зазвичай, обирають рівним 3 або 4, що свідчить про завершення перехідного процесу.

\section{Висновки}

1. Використання методу електрогідравлічної аналогії, заснованому на застосуванні теорії електри- чних кіл, для математичного моделювання роботи гідравлічних систем, створення нового або удосконаленого існуючого обладнання цих систем, 3'ясування особливостей їх експлуатації дозволяє суттєво спростити розрахунок гідравлічних кіл та наглядно і просто виконати аналіз їх роботи.

2. Відповідно до методу електрогідравлічної аналогії будь-яку гідравлічну систему можливо представити як електричне коло, аналогом напруги в якому є тиск рідини, аналогом струму є витрата рідини, а елементами цього кола $є$ гідравлічний активний опір, гідравлічна індуктивність і гідравлічна ємність.

3. Метод електрогідравлічної аналогії можливо використовувати для визначення технічного стану таких гідравлічних систем бензинового та дизельного двигуна внутрішнього згоряння як система паливоподачі, система змащення та система охолодження.

4. При оцінюванні технічного стану гідравлічних систем бензинових або дизельних двигунів внутрішнього згоряння з використанням методу електрогідравлічної аналогії в якості діагностичних параметрів доцільно застосовувати такі фізичні величини цих систем як тиск та витрата й визначати технічний стан обладнання гідравлічних систем, обираючи для цього в якості діагностичних показників зміну амплітудних, частотних, фазових та часових характеристик динамічних кіл, створених гідравлічними активними опорами, гідравлічними індуктивностями та гідравлічними ємностями.

\section{СПИСОК ЛІТЕРАТУРИ}

1. Аронзон Н.З., Козлов В.А., Козобков А.А. Применение электрического моделирования для расчета компрессорных станций. - М.: Недра, 1969. - 178 с.

2. Костишин В.С. Моделирование режимов работы центробежных насосов на основе электрогидравлической аналогии. - М.: Ивано-Франковск. - ИФДТУНТ, 2000. - 115 с.

3. Дружинин Н.И. Метод электродинамических аналогий и его применение для исследования фильтрации. - М.: ГЭН, 1956. $-155 \mathrm{c}$.

4. Попов Д.Н. Нестационарные гидромеханические процессы. - М.: Машиностроение, 1982. - 239 с.

5. Kuchuk G., Nechausov S., Kharchenko, V. Two-stage optimization of resource allocation for hybrid cloud data store. International Conference on Information and Digital Technologies. 2015. P. 266-271. DOI: http://dx.doi.org/10.1109/DT.2015.7222982

6. Коваленко А.А. Сучасний стан та тенденції розвитку комп'ютерних систем об'єктів критичного застосування / А.А. Коваленко, Г.А. Кучук // Системи управління, навігації та зв’язку. - Полтава . ПНТУ, 2018. - Вип. 1(47). C. 110-113. DOI : https://doi.org/10.26906/SUNZ.2018.1.110

7. Mohammed, A. S. Optimal Forecast Model for Erbil Traffic Road Data. ZANCO Journal of Pure and Applied Sciences. 2017. Vol. 29, No 5. P. 137-145. DOI: https://doi.org/10.21271/ZJPAS.29.5.15

8. Saravana, Balaji B,, Karthikeyan, N.K. and Raj Kumar, R.S., (2018), "Fuzzy service conceptual ontology system for cloud service recommendation", Computers \& Electrical Engineering, Vol. 69, pp. 435-446, DOI: https://doi.org/10.1016/j.compeleceng.2016.09.013

9. Gomathi B, Karthikeyan N K, Saravana Balaji B, "Epsilon-Fuzzy Dominance Sort Based Composite Discrete Artificial Bee Colony optimization for Multi-Objective Cloud Task Scheduling Problem", International Journal of Business Intelligence and Data Mining, Volume 13, Issue 1-3, 2018, pages 247-266, DOI: https://doi.org/10.1504/IJBIDM.2018.088435

10. Dhivakar B., Saravanan S.V., Sivaram M., Krishnan R.A. Statistical Score Calculation of Information Retrieval Systems using Data Fusion Technique". Computer Science and Engineering. 2012. Vol. 2, Issue 5. pp.43-45. doi: http://doi.org/10.5923/j.computer.20120205.01

11. Sivaram M., Yuvaraj D., Amin Salih Mohammed, Porkodi, V., ManikandanV. The Real Problem Through a Selection Making an Algorithm that Minimizes the Computational Complexity. International Journal of Engineering and Advanced Technology. 2018. Vol. 8, iss. 2. pp. 95-100.

12. G. Kuchuk, A. Kovalenko, I.E. Komari, A. Svyrydov, V. Kharchenko. Improving big data centers energy efficiency: Traffic based model and method. Studies in Systems, Decision and Control, vol 171. Kharchenko, V., Kondratenko, Y., Kacprzyk, J. (Eds.). Springer Nature Switzerland AG, 2019. Pp. 161-183. DOI: http://doi.org/10.1007/978-3-030-00253-4_ 8

13. Kuchuk G., Kharchenko V., Kovalenko A., Ruchkov E. Approaches to selection of combinatorial algorithm for optimization in network traffic control of safety-critical systems. East-West Design \& Test Symposium (EWDTS). 2016. Pp. 1-6. doi:https://doi.org/10.1109/EWDTS.2016.7807655. 
14. G. Kuchuk, A. Kovalenko, V. Kharchenko, A. Shamraev, "Resource-oriented approaches to implementation of traffic control technologies in safety-critical I\&C systems" in book: Green IT Engineering: Components Network and Systems Implementation, Springer International Publishing, vol. 105, pp. 313-338, 2017.

15. Атабеков Г.И. Теоретические основы электротехники. Часть 1. - М.: Энергия, 1966. - 320 с.

16. АС СССР №352169. Способ оценки технического состояния двигателя внутреннего сгорания. М.Кл ${ }^{3}$. G01M 15/00, 1972 г.

17. Льюис Э., Стерн. К. Гидравлические системы управление. - М.: Мир, 1966. - 394 с.

18. АС СССР №896466 Способ оценки технического состояния двигателя внутреннего сгорания. Б.Т. Кононов, К.Г. Сергеев, В.К. Терещенков, В.И. Тимошкин, Ю.Д. Шевцов М.Кл‥ G01M 15/00, от 13.05.1980, опубликовано 07.01.1982 бн.№1

19. Сторожев В.Н. Определение сроков службы масла в судовых дизелях с помощью автомата Двигателестроение, 1980, №3, c. 40-42.

20. АС СССР №966525 Способ оценки технического состояния двигателя внутреннего сгорания. Б.П. Байков, В.Т. Егоркин, Б.Т. Кононов, В.З. Ройк, К.Г. Сергеев, Р.3. Тараховский, Ю.Д. Шевцов. М.Кл‥ G01M 15/00, от 03.04.1981, опубликовано 15.10.1981 бн.№38.

Рецензент: д-р техн. наук, проф. Б. Г. Любарський,, Національний технічний університет “Харківський політехнічний інститут”, Харків Received (Надійшла) 08.04.2019 Accepted for publication (Прийнята до друку) 15.05.2019

\section{Использование электрогидравлических аналогий при диагностировании технического состояния бензиновых и дизельных двигателей внутреннего сгорания}

Б. Т. Кононов, Ю. Д. Мусаирова, О. Е. Куян

Выясняется связь между явлениями, происходящими в гидравлических и электрических системах путем сравнения процессов движения жидкости в магистральных нефтепроводах и процессов, происходящих в линиях электропередачи с распределенными параметрами. Устанавливаются гидравлические и электрические аналоги, а именно давление жидкости и напряжение, расход жидкости и ток, гидравлический круг представлен в виде электрической цепи, определяются понятия гидравлического активного сопротивления, гидравлической индуктивности и гидравлической емкости. Предлагается рассматривать гидравлические системы как динамические звенья, изменения значений параметров которых целесообразно применять для оценки технического состояния бензиновых или дизельных двигателей внутреннего сгорания, используя при этом такие физические величины, которые характеризуют работу систем двигателей, как давление и расход жидкости, и определяя техническое состояние этих систем путем выяснения изменения амплитудных, частотных, фазовых и временных характеристик динамических цепей, созданных гидравлическими активными сопротивлениями, гидравлическими индуктивностями и гидравлическими емкостями.

Ключевые слов а : двигатели внутреннего сгорания, электрогидравлические аналогии, динамические звенья, гидравлическое активное сопротивление, гидравлическая индуктивность и гидравлическая емкость, техническая диагностика гидравлических систем.

\section{Use of electro-hydraulic analogies in diagnosing the technical condition} of petrol and diesel engines for internal combustion

\section{B. Kononov, Yu. Musairova, O. Kuyan}

This article clarifies the relationship between the phenomena occurring in hydraulic and electrical systems by comparing the processes of fluid flow in trunk pipelines and the processes occurring in power lines with distributed parameters. It turns out how it is possible to use the basic provisions of the electro-hydraulic analogy for the analysis of the technical condition of the lubrication systems, cooling and fuel supply of gasoline and diesel engines of autonomous and backup power plants and power plants of samples of armored and automotive vehicles. Hydraulic and electrical analogues are established, namely, fluid pressure and voltage, fluid flow and current, the hydraulic circle is represented as an electrical circuit, the concepts of hydraulic resistance, hydraulic inductance and hydraulic capacity are defined. It is proposed to consider hydraulic systems as dynamic links, changes in the values of which parameters should be used to assess the technical condition of gasoline or diesel internal combustion engines, using such physical quantities that characterize the operation of engine systems such as pressure and fluid flow, and determining the technical condition of these systems by identifying changes in the amplitude, frequency, phase and time characteristics of dynamic circuits created by hydraulic actuators resistances, hydraulic inductances and hydraulic capacitances. The purpose of this article is to substantiate the possibility of using electro-hydraulic analogies when evaluating the technical condition of diesel and gasoline engines. Using the method of electro-hydraulic analogy, which is based on the application of the theory of electrical circuits, for mathematical modeling of hydraulic systems, creating new or improved existing equipment of these systems, determining the features of their operation can significantly simplify the calculation of hydraulic circuits and also visually and simply perform an analysis of their work.

Keywords: internal combustion engines, electro-hydraulic analogies, dynamic links, hydraulic resistance, hydraulic inductance and hydraulic capacity, technical diagnostics of hydraulic systems. 